Fanum

Sociológico
Forum Sociológico

Série II

17 | 2007

Envelhecimento activo. Um novo paradigma

\title{
Envelhecimento activo : complementariedades e contradições
}

Ana Paula Gil

\section{OpenEdition}

1 Journals

Edição electrónica

URL: https://journals.openedition.org/sociologico/1609

DOI: 10.4000/sociologico.1609

ISSN: 2182-7427

Editora

CICS.NOVA - Centro Interdisciplinar de Ciências Sociais da Universidade Nova de Lisboa

Edição impressa

Data de publição: 1 janeiro 2007

Paginação: 25-36

ISSN: 0872-8380

\section{Refêrencia eletrónica}

Ana Paula Gil, «Envelhecimento activo : complementariedades e contradições», Forum Sociológico

[Online], 17 | 2007, posto online no dia 01 janeiro 2007, consultado o 30 março 2022. URL: http:// journals.openedition.org/sociologico/1609; DOl: https://doi.org/10.4000/sociologico.1609 


\title{
ENVELHECIMENTO ACTIVO: COMPLEMENTARIDADES E CONTRADIÇÕES
}

\author{
Ana Paula Gil \\ Socióloga, Investigadora no INSA (paugil2@gmail.com)
}

\begin{abstract}
Resumo
O envelhecimento activo tem sido abordado a partir de duas perspectivas bem distintas. Uma perspectiva que faz da participação económica das pessoas mais velhas a pedra angular para a própria sustentabilidade financeira do Sistema de Segurança Social e para o cumprimento da Estratégia Europeia para o Emprego (EEE) e uma outra perspectiva que faz da "actividade" no envelhecimento o elemento estruturante para a ruptura face ao envelhecimento-incapacidade. Ambas as perspectivas incorrem em contradições e ambas exigem políticas sociais coerentes e sustentadas. O envelhecimento activo, do ponto de vista da saúde, requer medidas inovadoras que promovam a participação e a optimização de estilos de vida mais activos e saudáveis que contribuam para a qualidade de vida das pessoas que envelhecem. O envelhecimento activo, como instrumento de combate às saídas precoces do mercado de trabalho, não pode ser dissociável de um conjunto de medidas que promovam a conciliação entre vida familiar e profissional.
\end{abstract}

Palavras-chave: envelhecimento activo; incapacidade; saída precoce do mercado de trabalho; conciliação entre vida familiar e profissional; políticas sociais.

\begin{abstract}
Active aging has been approached by two completely different perspectives: the first one has its focus on the economic participation of the elderly, as the angular stone for the Social Security System sustainability and for the accomplishment of the European Employment Strategy (EES). The second one focuses on "activity" as the key-element to perform a rupture with the association of ageing and incapacity. Both perspectives present contradictions and both dem and for coherent and sustainable social policies. From a health perspective, active aging requires innovative interventions that promote participation and an optimization of life styles so that people have better quality of life as they age. Active aging seen as a tool to prevent an early leave of the labour market should be associated with measures that promote the conciliation between family and professional life.
\end{abstract}

Keywords: active aging; incapacity; labour market early leave; family and professional life conciliation; social policy.

\section{O envelhecimento activo: actividade versus incapacidade}

Com o intuito de valorizar a última etapa da vida, a Organização Mundial de Saúde definiu, na II Assembleia Mundial sobre o envelhecimento em 2002, o conceito de envelhecimento activo como "o processo de optimização das oportunidades para a saúde, participação e segurança, para melhorar a qualidade de vida das pessoas que envelhecem" (WHO, 2002:12).

Olhar para o envelhecimento de uma forma positiva e como uma oportunidade tem subjacente uma visão que pretende reabilitar a representação negativa do que é ser velho nas sociedades contemporâneas, por vezes retratados como um "fardo", "um peso" numa sociedade onde o economicam ente produtivo e o ser jovem é sobrevalorizado em detrimento do que é, socialmente, improdutivo. Tornar-se fisicam ente debilitado, incapacitado e mentalmente dependente face a outrem, são características por vezes generalizadas, a qualquer indivíduo que faça parte deste grupo social com mais de 65 anos (Thomas, 1996; Ennuyer, 2002), apesar da realidade demonstrar que a velhice pode ser uma etapa da vida, rica em experiências sociais e economicam ente 
úteis, fonte de bem-estar, qualidade de vida e de boa saúde.

As alterações das estruturas demográficas têm sido acompanhadas com acréscimos, em anos de vida, possibilitados pela diminuição da mortalidade sobretudo da mortalidade infantil, e, por consequência, do aumento da esperança de vida, decorrente da melhoria das condições de vida e da qualidade dos serviços de saúde.

Em 2004, a esperança de vida à nascença $\left(e_{0}\right)$ para os homens, em Portugal, era de 74,9 anos, valor ligeiramente abaixo da média da União Europeia (EU25), 75,1 anos, constituindo Portugal o país da Europa com a mais baixa esperança de vida masculina à nascença ${ }^{1}$. A esperança de vida para as mulheres portuguesas situava-se em 81,4 anos, valor relativamente superior à média europeia, 81,2 anos para U.E.25 (Eurostat, 2006).

Significativos são também os ganhos da esperança de vida aos 65 anos entre 1970 e 2004, pois estima-se que os homens que atinjam os 65 anos vivam em média mais 16 anos e as mulheres mais 19 anos. Apesar das diferenças entre homens e mulheres, em termos de esperança de vida, pela maior sobremortalidade masculina, registam-se, neste mesmo período, "ganhos traduzidos em 1,65 anos de vida para as mulheres e 1,63 para os homens. Enquanto que os homens que chegam aos 80 anos, podem viver mais um ano do que dez anos antes, as mulheres conseguiram um ganho mais modesto (0,7 anos)" (Carrilho e Patrício, 2005: 128).

Ainda que a esperança de vida dos homens seja inferior em todos os grupos etários, quando comparada à das mulheres, a percentagem de anos que os homens podem viver sem incapacidade, é superior à das mulheres. Partindo do grupo etário de 85 e mais anos verifica-se que a esperança de vida feminina é de 4,56 anos, dos quais só 0,44 poderão ser vividos sem qualquer tipo de incapacidade $(9,7 \%$ da esperança de vida deste grupo etário), o que significa que as mulheres vivem mais tempo, mas com mais incapacidade. A esperança de vida masculina é menor, correspondendo a 3,87 anos no grupo etário dos $85+$ anos, mas, em contrapartida, poderão viver 0,52 anos sem nenhuma incapacidade $(13,4 \%$ da sua esperança de vida), independentemente da natureza da incapacidade (INE, 2000:11).

Duas conclusões poderão ser retiradas: em primeiro lugar, a incapacidade atinge sobretudo as idades mais avançadas ${ }^{2}$ e a maior prevalência da incapacidade severa ocorre nos grupos etários com mais de 75 anos, em segundo lugar, atinge, em maior percentagem, o grupo das mulheres.

Os cenários demográficos mais recentes projectam a esperança de vida à nascença, próxima dos 85 anos para as mulheres e 79 para os homens, até 2050 (Magalhães, 2002); o que significará um aumento da proporção dos mais velhos, particularmente acentuado no grupo etário dos 80 e mais anos de idade. Esta evolução, que constitui, em si, um enorme ganho em saúde, conduziu ao aumento de pessoas idosas na nossa sociedade. Actualmente a população com mais de 65 anos ronda os $16,5 \%$ e as projecções demográficas indicam que 2050 a população atinja os 32\% (Magalhães, 2002). Este facto leva-nos a interrogar qual a evolução futura da saúde e da incapacidade no processo de enveIhecimento?

Em torno deste debate existem algumas perspectivas mais pessimistas que apontam para que exista no futuro um aumento das doenças crónicas. Kramer (1980) fala mesmo em pandemia dos problemas mentais, doenças crónicas e incapacitantes, em que o aumento da esperança de vida é geradora de uma maior duração da perturbação da capacidade funcional. Segundo esta teoria, para além do aumento das doenças degenerativas associadas ao envelhecimento, a consequência da quebra da mortalidade será o prolongamento no tempo das doenças crónicas e da manifestação da incapacidade funcional.

Para outros autores, mais optimistas como Manton, a esperança de vida sem incapacidade acompanha a evolução da esperança de vida total. O "equilíbrio dinâmico" entre a duração da vida (compressão da mortalidade) e a qualidade dos anos vividos (compressão da morbilidade) far-se-á paralelamente. Segundo esta teoria, a prevalência das doenças crónicas aumentará com a redução da mortalidade; mas os estados crónicos serão menos severos, menos incapacitantes (Morbiche, 1997:99).

E uma terceira perspectiva, proposta por Fries (1998), defende a "compressão da morbilidade" e o retardamento da incapacidade para as idades mais avançadas. A adopção de estilos de vida mais saudáveis e o avanço da medicina provocam não só uma redução da taxa de mortalidade, como permitem que as doenças crónicas e as incapacidades funcionais sofram um "processo de compressão"; isto é, que se manifestem durante períodos cada vez mais curtos no final da vida.

Embora estas perspectivas partam de cenários hipotéticos, o estudo longitudinal de Peres e Barberger-Gateau (2001) veio demonstrar que, no decurso de 10 anos, existiu uma importante progressão da autonomia entre duas gerações de indivíduos entre os 75 e os 84 anos, verificando-se, em simultâneo, uma baixa da incapacidade e um aumento da esperança de vida, corroborando assim a hipótese de Fries (1980). Este estudo veio ainda revelar que, apesar dos ganhos em saúde, as desigualdades sociais, segundo o sexo e o nível de escolarização, são variáveis que intervém no aparecimento da incapacidade. 
Se de um ponto de vista mais optimista as gerações mais velhas irão usufruir de uma melhor qualidade de vida, por disporem de melhores recursos educacionais, culturais, económicos que lhes permitirão fazer face aos novos desafios sociais, para os mais pessimistas, o envelhecimento demográfico gerará consequências inevitáveis nos sistemas de protecção social e de saúde, bem como irá exigir um maior encargo para as famílias.

Muito embora alguns destes estudos (Barberger- Gateau e Peres, 2001) tenham permitido chegar a alguns resultados "mais optimistas" relativamente à evolução da saúde das populações, não significa que as idades mais avançadas fiquem imunes à incapacidade, o que não deixará de se colocar como um problema para as próximas gerações e constituir assim, um novo risco social.

\section{O envelhecimento activo como instrumento de participação económica}

Para além do envelhecimento activo ser perspectivado do ponto de vista da saúde, este conceito foi apropriado, no âmbito da Estratégia Europeia para o Emprego (EEE), como um instrumento de participação económica. O envelhecimento activo é definido como "o conjunto de orientações e acções de natureza política que visam assegurar uma maior participação económica dos grupos etários mais velhos ainda em idade activa" (Pestana, 2003: 13).

No âmbito da Estratégia Europeia para o Emprego, a promoção do envelhecimento activo constitui uma linha orientadora da Política de Emprego dos Estados-Membros, na qual foram definidas duas metas a alcançar até 2010. São elas: "aumentar em cerca de 5 anos a idade média efectiva da saída do mercado de trabalho na União Europeia e elevar para $50 \%$ a taxa média de emprego de homens e mulheres entre os 55 e os 64 anos". Estas metas inserem-se, quer na necessidade de reduzir os efeitos económicos e sociais das actuais tendências demográficas nos sistemas de segurança social e nos mercados de trabalho nacionais, quer no que se refere ao desequilíbrio entre activos e inactivos, pelo envelhecimento da população activa (Pestana, 2003).

Uma das estratégias recomendadas pelo Conselho Europeu, no âmbito da EEE, a Portugal é a de "desenvolver uma estratégia global de envelhecimento activo que elimine os incentivos à reforma antecipada, reforce o acesso à formação e garanta condições de trabalho adequadas" (MTSS, 2005:17).

Portugal destaca-se na realidade europeia por apresentar uma das mais elevadas taxas de participação económica dos grupos etários mais velhos da população em idade activa, acima da média Europeia (41\%, em 2004). Se tivermos em conta as estatísticas nacionais referentes aos trabalhadores mais velhos, a taxa de emprego dos trabalhadores com 55 anos ou mais anos era, em 2004, 50,3\% (51,6\%, em 2003), situando-se ligeiramente acima da meta europeia assumida para 2010 (50\%)" (MTSS, 2005:32).

A estratégia global do envelhecimento activo, para além de combater o abandono precoce do mercado de trabalho, tem também contemplada nas suas recomendações a criação de medidas de combate à diferenciação salarial entre homens e mulheres, através também do acesso a estruturas de acolhimento a crianças e outros dependentes (deficientes, idosos).

Se analisarmos a evolução estatística da actividade profissional feminina, na última década, conclui-se, por um lado, a tendência crescente para o emprego feminino, a tempo inteiro, e, por outro lado, a redução do emprego em idades mais velhas.

Os dados nacionais permitem verificar que, em 2001, continuamos a ser o sexto país da União Europeia, com a maior taxa de actividade feminina, no grupo etário dos 15 aos 64 anos $(68,7$, valor acima da média da EU-15, 64,1) e, também, o quinto país com a maior percentagem de mulheres empregadas, entre os 55-64 anos (50,1, valor muito acima da média da EU-15, 38,8) (Eurostat, 2002).

Contudo, as estatísticas nacionais indiciam que o peso do trabalho a tempo inteiro se reduz à medida que a idade avança, sendo que a maior concentração de mulheres a trabalhar a tempo parcial se situava na faixa etária dos 40 aos 59 anos (INE, 2004), faixa etária mais susceptível também, de abandonar o mercado de trabalho. Esta saída precoce do mercado de trabalho prende-se com um conjunto de razões: desemprego, problemas de saúde e razões de ordem familiar (Perista et al, 1997). Em relação a este último factor, o INE (1999) veio também confirmar a forte representação das mulheres com mais de 55 anos, na prestação de cuidados a outros familiares.

Mas se a estratégia do emprego é prolongar a idade da reforma (pela sustentabilidade do próprio Sistema da Segurança Social), por muito mais anos $^{3}$, e combater a saída precoce do mercado de trabalho, esta estratégia pode originar dois possíveis problemas.

- Por um lado, iremos trabalhar até mais tarde, possivelmente até aos 70 anos, partindo do pressuposto que estamos saudáveis, e do ponto de vista da saúde se concretize a tese de Fries para a compressão da morbilidade, ou seja, que o surgimento da incapacidade se inicie em idades mais avançadas (> 80 anos). O problema coloca-se em relação aos trabalhadores mais velhos, já em situação de doença crónica e com índices de incapacidade 
consideráveis, certamente que irão debater-se com obstáculos importantes em termos de produtividade e da própria qualidade do trabalho, mesmo devidamente formados e qualificados.

- Por outro lado, para além da doença, as responsabilidades familiares são um dos principais factores do abandono do mercado de trabalho. A disponibilidade de prestar cuidados a pessoas em situação de incapacidade corre o risco de ser mais restrita, sobretudo em países onde a taxa de actividade feminina é mais elevada, como é o caso de Portugal, em que a tensão entre cuidados e trabalho se pode acentuar (Jacobzone e Robine, 2000).

As alterações que se estão a processar, na sociedade portuguesa, em termos das novas configurações familiares (redução do tamanho da família; o aumento das famílias unipessoais, das uniões de facto e do recasamento) e a maior taxa de actividade feminina, podem ter consequências na capacidade das gerações mais novas em cuidarem dos seus familiares. Esta perspectiva é defendida por alguns autores (Jong-Gierveld et.al., 1995; González, 2001) que sustentam que a evolução da família e do emprego podem conduzir a uma redução da capacidade de participação familiar nos cuidados, sempre que a dependência ocorra na vida familiar. No entanto, esta questão não é consensual, para outros autores (Sundstrom, 1994), embora possa existir uma redução no "reservatório das potenciais ajudas", os seus valores não permitem, de forma plausível, fazer previsões temporais sobre a disponibilidade das solidariedades familiares. No entanto, uma coisa é certa, a probabilidade de cuidar de um familiar (cônjuge, ascendente) irá colocar-se cada vez mais nas próximas gerações, como poderá implicar também uma profunda mudança de valores, práticas e de referências normativas.

Apesar da divergência de perspectivas em torno desta questão, estes autores são, contudo, consensuais relativamente a algumas tendências:

- A diminuição da mortalidade provoca um adiamento na idade em que possa ocorrer a viuvez e com o aumento da longevidade a tendência será para uma convivência conjugal mais longa;

- Os cuidados irão ser prestados somente por um filho, contrariamente à descendência actual composta por três filhos (Sundstrom, 1994), pela redução do número de filhos. A consequência mais directa será, certamente, a polarização das responsabilidades familiares, num único elemento;

- Com a fecundidade e a mortalidade baixas, a tendência é para se criar uma situação em que a dimensão média dos agregados domésticos se reduza e aumente a idade média dos seus elementos. A consequência im ediata destas novas configurações familiares será uma maior intervenção das gerações adultas, agora mais reduzidas, compostas por cônjuges e filhos, cada vez mais velhos e, por vezes, já incapacitados para prestar apoio;

- O aumento das pessoas que vivem só, sem descendência, pessoas idosas solteiras ou divorciadas, com uma rede familiar restrita, e que irão constituir-se, certamente, como potenciais candidatos aos estabelecimentos colectivos ou aos serviços na comunidade.

Se passámos de um modelo de família, extenso e rural, onde a mulher era quem cuidava das crianças, dos doentes e dos idosos da família, hoje estamos perante um modelo de família nuclear urbano, em que a mulher concilia a sua actividade profissional com a vida familiar. Este facto leva-nos para um conjunto de interrogações: Como é que os cuidadores, inseridos no mercado de trabalho, conciliam trabalho e família quando surge uma situação de incapacidade severa no seio familiar? Que estratégias utilizam para tornar compatível tempos laborais com tempos de família? Qual o significado, para estes, do valor do trabalho? Foram estas, entre outras, algumas das questões a que o estudo "Heróis do quotidiano: dinâmicas familiares na dependência", pretendeu responder ${ }^{4}$.

\section{A conciliação entre trabalho e cuidados familiares na dependência: significados, práticas e estratégias de acção - resultados de um estudo empírico}

A questão da conciliação do trabalho e da vida familiar, na qual se incluem os cuidados na dependência, tem sido abordada teoricamente a partir de uma perspectiva predominantem ente feminina, em que 0 enfoque tem tido pouco em conta a questão do género e o homem surge perspectivado, muitas vezes, de forma secundária ou ausente. Esta polarização feminina, poderá ser explicada pela sobrerepresentação das mulheres, ao nível dos cuidados, como vieram comprovar vários estudos desenvolvidos em Portugal sobre as solidariedades familiares (Quaresma, 1996; Fernandes, 1997; Gil, 1998; Wall et al. 2002; Torres et al., 2004) e na Europa.

Segundo a Eurostat (2003) "6\% dos Europeus prestam apoio a adultos deficientes e idosos e é o grupo dos $50-59$ anos (11\%) que presta mais apoio, e as mulheres $(8 \%)$ duas vezes mais do que os homens (4\%)" (Eurostat, 2003: 99-100).

Apesar destas estatísticas, pouco se sabe sobre a situação real dos trabalhadores que têm pessoas 
dependentes a cargo ao longo da Europa. Anderson (1998) refere o relatório de Schneekloth e Potthoff (1993) ao demonstrar que " $72 \%$ dos cuidadores de pessoas dependentes (de todas as idades) não estão inseridas no mercado de trabalho, $5 \%$ trabalham esporadicamente, $7 \%$ a tempo parcial e $10 \%$ a tempo integral". Este estudo refere ainda que destes prestadores (dos 18 e os 64 anos), dois terços estavam a trabalhar quando iniciaram a prestação de cuidados, o que significa que pelo menos um quarto deixou de trabalhar e uma percentagem idêntica reduziu o número de horas de trabalho. O autor refere ainda que a prestação de cuidados na família é razão suficientemente forte para se desistir de um trabalho remunerado (Anderson, 1998:188).

Por considerarmos que se conhece muito pouco sobre a forma como as famílias hoje conciliam trabalho e cuidados familiares, sempre que a dependência ocorra no seio familiar, realizámos um estudo empírico composto por 52 entrevistas (semi-estruturadas) a famílias cuidadoras de pessoas adultas em situação de incapacidade severa, na Área Metropolitana de Lisboa ${ }^{5}$.

Os dados deste estudo empírico permitiram revelar diferenças de género, relativamente à forma como se conciliam responsabilidades familiares e profissionais no apoio à dependência ${ }^{6}$.

Entre a população masculina conclui-se que o estatuto profissional dita a maior ou menor flexibilidade com que se concilia a vida profissional e a vida familiar; além do factor financeiro ser determinante no recurso a apoios profissionais remunerados. Sempre que não existem condições financeiras, quase sempre há um familiar voluntário (irmã, cunhada, filha) que substitui as ausências. Na prática, a população masculina recebia apoio quer familiar, quer profissional e todos os entrevistados concebiam o trabalho como uma "fuga" à situação.

Entre a população feminina o trabalho significava, para a maioria, a fonte de rendimento, por vezes, até mesmo a única, e a fonte emocional. O trabalho é encarado como um tempo de ruptura e de distanciamento físico face à situação. Para outras entrevistadas, cuidar a tempo inteiro seria um cenário traçado impossível pelo risco de desequilíbrio físico e psicológico da própria cuidadora. Para as gerações mais novas (filhas) o trabalho é o único modo de vida, um investimento; para os cônjuges femininos, um sacrifício ou, até mesmo, uma obrigação; pois não existem alternativas possíveis senão a saída precoce do mercado de trabalho ou a reforma antecipada. Para outras ainda, o trabalho "era tudo" para deixar de o ser, dado que foi algo que se abandonou porque era necessário cuidar a tempo inteiro do familiar.

Para as filhas, as únicas razões possíveis para o terminus dos cuidados no domicílio são o agravamento do estado de saúde do familiar, o surgi- mento de uma doença grave ou, ainda, a falta de recursos financeiros para pagar a um profissional ou a um serviço.

A maioria das filhas pretende continuar a cuidar até ao máximo de tempo possível, referindo que não pode abandonar o trabalho, por vezes, a única fonte de sobrevivência, mesmo que para isso seja necessário recorrer a um lar de idosos, solução que se apresenta como o último desejo.

Em ambos os discursos, de homens e mulheres, emerge a dificuldade que é conciliar tempos de trabalho com tempos de família, metaforicamente associada a uma permanente corrida entre a casa e o local de trabalho e do local de trabalho para casa.

A conciliação é encarada como uma "luta", sempre que as condições económicas limitam o recurso a um apoio particular ou se está dependente de um familiar disponível, quase sempre reformado ou desempregado, com quem se possa contar com a presença física durante o dia. Quando não existem condições financeiras para pagar a alguém ou um serviço (centro de dia ou um serviço de apoio domiciliário) ou, até mesmo, porque o familiar se encontra numa situação de grande fragilidade física faz com que o familiar fique só durante o dia.

A coabitação, como estratégia de conciliação, só se coloca quando o familiar é viúvo(a) porque não existem condições para se viver só ou ainda porque a partilha da mesma residência era anterior ao surgimento da doença. Se por um lado, a coabitação flexibiliza tempos e espaços de cuidados, por outro lado, avoluma tarefas, quase sempre iniciadas pela manhã e prolongadas ao longo da noite, após um dia de trabalho.

Um dia normal de trabalho é, quase sempre, antecedido por um verdadeiro trabalho de cuidados: noites mal dormidas; cuidados a prestar logo pela manhã ou a espera de alguém que substitua. Antes de se sair para o trabalho, é necessário deixar preparado o cônjuge ou pai/mãe, o que significa quase sempre levantar às $5 \mathrm{~h}, 6 \mathrm{~h}$ da manhã para dar banho, mudar a fralda, medicar e dar de comer ao familiar, podendo ser feito só, ou ainda partilhado entre uma filha e um cônjuge, sobretudo feminino. Quando se está só, o tempo de saída fica condicionado pela chegada de um terceiro elemento, quase sempre de uma empregada particular ou de uma ajudante familiar, oriunda de um serviço de apoio domiciliário. Sempre que não existem condições financeiras, então o familiar fica só.

Chegadas aos empregos, é a preocupação, é a vigilância permanente através do telefone. A hora de almoço é, quase sempre, transformada num tempo de cuidados e uma oportunidade para regressar a casa, a fim de ajudar a dar de comer ao familiar ou simplesmente, supervisionar quem está na linha da frente dos cuidados (familiar ou não familiar). Esse tempo de descanso pode ser ainda, 
transformado em tempo de compensação em horas de trabalho a fim de possibilitar não só a entrada mais tarde ou, em oposição, a saída do trabalho mais cedo. O regresso ao trabalho é acompanhado pela permanente preocupação sobre o que é necessário assegurar: compras, medicamentos, fraldas, produtos, contactos, pagamentos, enfim, planear os próximos dias.

Finda a hora de trabalho, é o regresso a casa que implica, após a aquisição do que se estipulou como necessário, a execução de actividades de cuidados: preparar o jantar, dar banho, mudar a fralda, mobilizar o familiar, dar de comer; sem falar, quando existe, o apoio aos filhos, geralmente adolescentes. Esta "roda - viva" reproduz-se, dia após dia, ano após ano, intensificando-se ao fim- de-semana, quando o volume das tarefas é maior, dada a inexistência de apoios formais, realidade generalizada entre os serviços de apoio domiciliário, ou, até mesmo, porque se dispõe de mais tempo.

Quando não existe coabitação com o familiar, mas supervisão à distância, o trabalho normalmente, funciona como um tempo de ruptura pela separação física que envolve; mas, em oposição, constitui uma continuação emocional face ao problema. O que une, ao mesmo tempo, estes cuidadores, é o facto das preocupações com os cuidados aos familiares, serem importadas para o tempo de trabalho, efectuando-se sucessivos contactos telefónicos, 3, 4, 5 vezes, de forma a supervisionar o trabalho de cuidados, ou, simplesmente, para planear ou engendrar modos de organização. Pelo telefone, também se controlam tempos de medicação, alimentação, sonos, disposições emocionais do familiar.

Terminado o trabalho, este subgrupo de cuidadoras, utiliza também a hora do almoço para prestar cuidados, tempo que é utilizado para dar de comer ou executar algum acto de higiene pessoal (por ex. mudar a fralda).

Quando existe um terceiro elemento, um cônjuge presente, o tempo após o horário de trabalho, serve para as filhas efectuarem pequenas visitas ao longo da semana, antes do regresso a casa, para onde se transportam compras, medicamentos, produtos de limpeza. Chegadas ao domicílio do familiar confere-se o que foi feito (pelo familiar ou pelos profissionais), efectuam-se actividades pessoais, (banho, vestir, mudar a fralda), por vezes sós, estima-se o que faz falta, em termos pessoais, (medicamentos, fraldas, produtos) ou domésticos; ou simplesmente, uma ocasião para os afectos.

Terminada a visita, no regresso a casa espera-as uma vida familiar e todas as actividades acumulativas domésticas, e não domésticas, prolongando-se por longas horas da noite.

Como se pode deduzir, o tempo de descanso e de lazer, é transformado, quase sempre, num tempo de cuidados, cujas múltiplas tarefas a planear, ou a executar têm, inevitavelmente, efeitos subtis no trabalho (Merill, 1997), por quem está envolvido, directamente ou indirectamente, na gestão dos cuidados ao familiar. A perda de produtividade, de motivação, assiduidade, as penalizações em termos de promoção profissional, as flutuações do rendimento, em função da emergência dos problemas quotidianos com a doença, constituem efeitos objectiváveis, e partilhados pelo universo dos entrevistados. O estatuto social e económico é um elemento diferenciador dos impactos que possam surgir desta conciliação, podendo ser subtis ou substanciais.

Mais do que um discurso de abandonar tempos de cuidados ou tempos de trabalho, este desenrola-se em torno da dificuldade de conciliar ambos, perspectivados como prioridades situadas ao mesmo nível, geridas em função das vicissitudes do momento.

Um dos problemas identificados pelos cuidadores prende-se com a questão da justificação das faltas. A compensação em horas, para além do horário de trabalho estabelecido, o fim-de-semana ou o uso da hora do almoço, numa primeira fase, servem para colmatar ausências. Estes são alguns dos mecanismos utilizados para gerir ausências; fundamentalmente, para acompanhar a consultas médicas ou saídas em situações de emergência, pelo agravamento do estado de saúde do familiar. Sempre que implique algumas horas, os cuidadores, geralmente, compensam essas horas por iniciativa própria. Numa segunda fase, quando as faltas ao trabalho se prolongam e se repetem sucessivamente, por vezes semanalmente, então recorre-se às férias, em dias ou na sua totalidade, como a única via possível, para prestar um apoio mais prolongado.

No presente estudo, verifica-se que a assistência à família é o último dos recursos a utilizar, sobretudo no regime geral da Segurança Social, quando as faltas são justificadas, mas não remuneradas, significando uma quebra salarial importante.

As nítidas desvantagens que existem entre o regime geral da Segurança Social e o regime de trabalho especial na Administração Pública emergem visivelmente, dos discursos dos entrevistados e fazem do direito social - a assistência à família - um verdadeiro "pau de dois bicos"

A afectação do vencimento é a justificação mais invocada para a não utilização da assistência à família, à semelhança das faltas, com repercussões naturais em termos de vencimento, subsídio de almoço ou em termos de prémios anuais. Embora a maioria dos cuidadores apresente uma justificação das faltas: por vezes, as saídas em momentos críticos, sem que seja necessário chamar um médico ou ir a uma urgência num hospital, torna a justificação da ausência um problema, quase sempre gerador de desconfiança ou conflito com as chefias, ainda 
mais, quando estas ausências se repetem interminavelmente, no tempo.

O acompanhar, o tratar de assuntos que digam respeito ao familiar, é um verdadeiro problema para quem tenha limitações em termos de flexibilidade de trabalho, directamente relacionada com o estatuto profissional usufruído. As faltas são tratadas como um assunto estritamente pessoal e incompatível com os interesses das organizações, sempre que estas situações extravasem o limite da razoabilidade; ou seja, a sua curta duração. Mas a curta duração não é compatível com a doença crónica que, por definição, é incurável, progressiva e prolongada.

Os efeitos subtis na esfera do trabalho, podem transformar-se em efeitos mais substanciais, quando a doença crónica se prolonga por tempo indeterminado; em que a saída precoce do mercado de trabalho, o desemprego, a reforma antecipada, as baixas, são as únicas formas que o cuidador encontra, quando a gravidade da situação se intensifica, para fazer face à doença.

A situação de inactividade, consequência do desemprego, e a ausência de alternativas possíveis, neste caso, a indisponibilidade de outros familiares, concorrem em conjunto, para acelerar a decisão para a assumpção dos cuidados, a tempo inteiro, e a pressão social desse estatuto levam, por vezes, a que o familiar se sinta "obrigado", "empurrado" definitivamente, para a aceitação desse novo papel.

A saída precoce do mercado de trabalho coloca-se sempre em situações de grande extremidade. $O$ anúncio da morte do familiar, sobretudo se for um doente oncológico; os conflitos laborais, devido às repetidas ausências e o aproximar dos anos de reforma, concorrem para que esta opção seja tomada, associada, também, a problemas de ordem física ou mental, após anos intermináveis de cuidados. A doença oncológica, entre as patologias em análise, surge como a mais devastadora, uma vez que o curto tempo de vida dos doentes propicia em quem cuida um sentimento de que é necessário, em primeiro lugar, prestar uma assistência permanente, em detrimento dos interesses individuais, mesmo que, para isso, represente abdicar de tudo, de uma profissão, de um rendimento e viver das poupanças acumuladas ao longo de uma vida.

Colectivamente esta opção - a saída precoce do mercado de trabalho - é entendida quase sempre como um "assunto" da esfera individual, familiar, onde nem o Estado, nem as empresas se devem imiscuir. No entanto, a Estratégia Europeia para o Emprego ao promover o envelhecimento activo, através do combate às saídas precoces do mercado de trabalho, não tem sido acompanhada na prática por uma política de família que responda às necessidades reais da dependência.

Se a criação de mais equipamentos sociais (infância e idosos) surge como a palavra-chave para esse combate, então não irá certam ente contemplar todos aqueles que são adversos à institucionalização e que não vêm outra saída senão abandonar o mercado de trabalho. Este custo é acarretado, unicamente, pela própria pessoa que faz esta opção; pois socialmente, não se premeiam todos aqueles que tomam esta decisão, ainda encarada como estritamente pessoal e não como uma questão social. Conclusão que vai ao encontro de um inquérito às medidas de apoio aos trabalhadores com pessoas idosas a cargo promovido pela CITE $(1995)^{8}$.

Num universo de 1000 empresas, o número de empresas sensíveis à questão da implementação de medidas de apoio a trabalhadores (as) com pessoas idosos a cargo, é muito reduzido; pois a maioria $(84,3 \%)$ não possui medidas específicas dirigidas a este tipo de assistência ${ }^{9}$. Este mesmo estudo conclui que a maioria dos dirigentes considera irrelevante estas medidas dado que os efeitos negativos provocados pelas faltas não são significativos ${ }^{10}$ e cerca de $20 \%$ refere, até mesmo, que não é da responsabilidade das empresas a adopção destas medidas (CITE, 1995: 22), cabendo ao Estado e à Segurança Social desenvolver este tipo de medidas.

Se não compete às empresas, se o Estado se demite, quem assume o custo social desta opção? A ausência de um quadro regulamentador que proteja todos aqueles que fazem a opção deliberada de associar trabalho com cuidados familiares, gera a subjectividade daqueles que vivem o problema e daqueles que os gerem profissionalmente que se debatem com esse problema, reconhecido sempre como estritamente pessoal e pertencente à esfera familiar. Os resultados deixam no "ar" uma interrogação: Quem protege a longo prazo o desgaste físico, psicológico, pelos problemas de saúde emergentes nos cuidadores, ou as saídas precoces do mercado de trabalho, as baixas ou o desemprego?

\section{Conciliação entre vidas familiares}

(de cuidados na dependência) e vida profissional: que políticas de apoio à família a promover?

Hoje reclama-se para uma maior intervenção das famílias no apoio aos mais velhos, sem que esse discurso seja acompanhado, efectivamente, por medidas práticas que fomentem a conciliação entre vida familiar e trabalho, quer em termos de apoios financeiros, (benefícios fiscais), flexibilidade no trabalho (horários de trabalho, justificação de faltas) ou em licenças de assistência à família, mais alargadas e compatíveis com a temporalidade da doenças crónica. Por outro lado, não existe uma política que proteja todos aqueles que saem do mercado de trabalho, por livre iniciativa, para cuidarem a tempo inteiro. 
Remeter a dependência para as responsabilidades familiares, como tem sido tradição na esfera pública, implica preparar, formar, apoiar, acompanhar e supervisionar tecnicamente, os cuidadores que se confrontam com um caminho árduo; muitas vezes, ausente de apoios profissionais e de serviços com qualidade.

São necessárias políticas sociais de apoio à família, sustentadas com uma política integrada de uma rede de cuidados continuados, que possam, efectivamente, apoiar quem opta por cuidar no domicílio. E, ao mesmo tempo, prevenir situações de desgaste físico e psicológico, ou situações mais graves, como o abandono dos idosos nos hospitais, face às adversidades que esta função exige, ou a violência familiar aos mais velhos, fenómenos com tendência a aumentar ou a tornarem-se, pelo menos, com maior visibilidade social ${ }^{11}$.

"A retórica moral", assente na noção de escolha, veiculada por parte do Estado é ilegítima dado que, por definição, "qualquer escolha implica alternativas" e a ausência de políticas e programas direccionados para as necessidades dos mais velhos, por parte do Estado, reflecte a assumpção da responsabilidade familiar na gestão da dependência (Montgomery, 1999:388).

Apesar das recomendações de Viena (AAVV, 1998) irem no sentido da necessidade de desenvolver uma política de família no apoio à dependência, só alguns países da Europa possuem uma política global e integrada que contemple um conjunto de medidas que favoreçam a conciliação do binómio família e trabalho. Entre as principais medidas destacam-se a flexibilidade dos horários de trabalho, a redução de horário (Espanha, Áustria, Finlândia), licenças de longa duração, não remuneradas ( 1 ano em Espanha, 2 anos em Itália), ou remuneradas, mas limitadas no tempo (60 dias na Suécia). Na Alemanha, se a pessoa prestar apoio por um período de 1 ano é concedida uma licença de quatro semanas para as famílias poderem descansar, através do acesso a residências temporárias. Ou ainda, o caso da Irlanda que possui, até mesmo, o regime "respite care scheme" (1993) ao facultar aos familiares que prestam apoio empréstimos financeiros para descanso temporário, férias ou fins-de-semana (Conselho da Europa, 1995; CITE, 2001; MISSOC, 2004).

A lei sobre "os cuidados destinados às pessoas idosas", na Suécia, em 1990, faz do suporte aos cuidadores, um dos principais objectivos da sua política da velhice. Esta política, além de prever "a assistência económica, permite uma licença para cuidar dos familiares (paga pelo sistema de doença), em situações de urgência ou no final de vida" (Delperee, 1998:286-287); e o acesso a uma rede, totalmente gratuita, de serviços integrados e diversificados de apoio social, saúde e reabilitação (Suécia, Dinamarca e Finlândia).
Outros países como a Alemanha, o Reino Unido e os países Nórdicos atribuem aos cuidadores o direito a uma pensão afim de proteger todos aqueles que saem do mercado de trabalho para prestar cuidados a tempo inteiro e conservar os seus direitos em matéria de reforma ou a atribuição de um subsídio afim de os compensar da perda de rendimentos (OCDE, 2005).

Enquanto que alguns países têm privilegiado uma estratégia centrada sobretudo nos cuidadores, outros países incidem a sua estratégia na renovação de uma melhor coordenação das responsabilidades entre os actores da saúde, cuidados de longa duração e na descentralização das prestações e dos programas (Reino Unido, Espanha, Finlândia, Dinamarca). Outros países ainda (Inglaterra, Alemanha, França e Estados Unidos) têm assistido, nas últimas décadas, à implementação de diferentes medidas tais como: a adaptação das habitações, a implementação de serviços de apoio domiciliário mais complexificados e diversificados, e a criação de pequenas estruturas de acolhimento ( 8 a 20 pessoas) com carácter mais especializado para pessoas que sofram de demências senis ${ }^{12}$. Na globalidade, não tem existido um modelo único de financiamento; e alguns países têm optado, até mesmo, por privilegiar um modelo misto, composto por soluções privadas, complementares às públicas.

Perante este cenário que políticas sociais a promover face à realidade portuguesa?

O diagnóstico real tecido pelos entrevistados no estudo "Heróis do quotidiano: dinâmicas familiares na dependência" sobre os serviços de apoio social não só permitiu obter um retrato social sobre os mesmos, como lançar um conjunto de medidas sociais a implementar no futuro, decorrentes da insatisfação face aos serviços que existem na comunidade em geral, pela inexistência, escassez e precariedade dos apoios formais. Reabilitar, criar, melhorar, descentralizar, fiscalizar são verbos, sucessivam ente utilizados pelos entrevistados, para traduzir a necessidade de se reestruturar o actual sistema de apoio à dependência. Entre as principais medidas destacam-se as seguintes:

- Rever o estatuto de cuidador no código de trabalho e na protecção entre trabalho e responsabilidades familiares, em termos de flexibilidade nos horários de trabalho, justificação de faltas, licença de assistência à família mais alargada e compatível com a doença crónica. É fundam ental o reconhecimento da figura do cuidador, como alguém que presta cuidados familiares; e que, ele próprio, necessita de ser protegido na doença e na reforma, pelo trabalho de cuidados desempenhado, não só pelo interesse individual, mas também público. A protecção social dos cuidadores 
prende-se com a forma como cada país define trabalho informal, como uma "prestação de serviços": inscrita num dever moral de solidariedade familiar ou numa responsabilidade social, que necessita de ser compensada e protegida, com uma remuneração base, ou contabilizada para o direito a uma reforma, aliás, medida já implementada em alguns países europeus (Alemanha Dinamarca, Noruega e Luxemburgo).

- Promover benefícios fiscais às famílias que optam por cuidar no domicílio. Actualmente, existem, até mesmo, medidas fiscais de apoio às famílias que colocam os familiares em lares usufruindo, para isso, de benefícios fiscais, em termos de IRS, contrariamente às famílias que optam por cuidar no domicilio, não existindo qualquer reconhecimento por parte do Estado no apoio que é prestado por estas mesmas famílias ${ }^{13}$

- Adequar o funcionamento dos serviços (serviços de saúde, apoio social), com horários mais alargados, compatíveis com quem trabalha, constitui outra das medidas mencionadas. A penalização no final do mês prende-se com a questão das faltas ao trabalho, com reflexos, muitas vezes, na esfera do trabalho, porque implica estar em permanente alerta, para eventuais saídas de emergência ou ausências para acompanhar o familiar a consultas médicas.

- Outra das preocupações mencionadas pelas famílias diz respeito aos custos financeiros com a doença e às crescentes despesas com consultas médicas, reabilitação (fisioterapia), medicamentos, fraldas, produtos dermatológicos, ambulâncias, ajudas técnicas, apoios colaterais que são essenciais para as famílias poderem fazer face às inúmeras despesas mensais.

- A falta de preparação pedagógica das altas hospitalares por alguns profissionais de saúde é outra preocupação referida por quem, de repente, se vê, "a braços" com uma pessoa, em situação de incapacidade. A saída do hospital significa o confronto com a dependência do familiar, famílias que nunca trataram de um doente, nem sabem como mudar uma fralda. São momentos de grande aflição para quem trabalha e tem que decidir sobre o destino do familiar, e é gerador de um verdadeiro dilema entre: encontrar um lar condigno, quando existe vaga, face a um mercado que nem sempre é garantia de qualidade de serviços e que acaba por ser bastante dispendioso do ponto de vista financeiro; ou recorrer a um serviço de apoio domiciliário, ainda que socialmente útil, se reduz a actividades de apoio social (a refeição, a higiene pessoal), num curto espaço de tempo (10, 15 minutos), tempos muito curtos para pessoas que necessitam de uma assistência permanente.

- Promover a formação e acompanhamento social/informativo e psicológico dos cuidadores, fomentados e apoiados por uma rede de cuidados continuados e paliativos, ao longo do território nacional, que respondam às necessidades efectivas das famílias que se confrontam com situações de incapacidade ou de final de vida. A actual Rede Nacional de Cuidados Continuados Integrados é uma esperança, pois da forma como está pensada e o esforço que tem sido desenvolvido, irá certamente responder em muito às necessidades das famílias.

- Promover mais formação, supervisão técnica dos recursos humanos que trabalham com pessoas em situação de incapacidade, devendo ser a formação (inicial e contínua) um requisito obrigatório no exercício das funções de cuidados formais.

Em conclusão, a evolução histórica das políticas sociais da velhice em Portugal tem sido parca na emergência de medidas inovadoras dirigidas no sentido de um envelhecimento activo, na promoção da participação, optimização de estilos de vida mais activos que contribuam para a qualidade de vida das pessoas que envelhecem: ao nível do habitat, do acesso à informação e às novas tecnologias; da educação ao longo da vida, no acesso a actividades de lazer, desportivas, culturais, voluntariado e de cidadania; quer ao nível das acessibilidades; da fiscalidade; da saúde ou, até mesmo, ao nível das próprias respostas sociais, na criação de uma rede diversificada, como os apartamentos, as residências medicalizadas, os centros de alívio temporário, os centros especializados para a demência, numa linha reabilitadora (terapia ocupacional, musicoterapia, entre outras).

Por um lado, é necessário repensar em novas políticas sociais integradas, assentes em modelos de equipam entos e serviços qualificados, bem como criar medidas concretas de apoio à família, no sentido de promover o exercício das responsabilidades familiares, além de se estar a prevenir, está-se a combater potenciais problem as sociais que poderão emergir nas próximas décadas. Por outro lado, não podem ser descuradas políticas que promovam a saúde, a participação, a optimização de estilos de vida mais activos e que contribuam para qualidade de vida das pessoas que envelhecem, pois indirectamente estamos a prevenir o surgimento de situações de incapacidade. 


\section{Notas}

1 Fernandes (2007) refere que esta desvantagem masculina se deve à elevada mortalidade em idades precoces devido a acidentes rodoviários ou laborais. Citando Santana (2005) a mortalidade em idades precoces relaciona-se com comportamentos de risco como são, os acidentes de viação, a promiscuidade nas práticas sexuais, o consumo de drogas, tabaco e álcool (p.427).

2 A incapacidade surge associada à idade, podendo ter origem numa doença crónica ou ser reflexo de uma perda das funções fisiológicas, atribuídas ao processo global da senescência (Manton, 1997 citado por Marin e Casasnovas, 2001:25).

3 Em 2003 a idade média de saída do mercado de trabalho situava-se nos 62,1 anos. Cf. MTSS, 2005, Plano Nacional de Emprego, p. 32.

${ }^{4}$ Gil, Ana Paula Martins (2007), Heróis do quotidiano: dinâmicas familiares na dependência, Dissertação de Doutoramento em Sociologia, Orientador: Ana Alexandre Fernandes, Faculdade de Ciências Sociais e Humanas da Universidade Nova de Lisboa.

5 Os critérios utilizados na selecção das famílias foram: homens e mulheres, que cuidem de familiares em situação de incapacidade severa; unidos por uma relação de parentesco (cônjuges, filhos, irmãos, sobrinhos, netos, noras, outros familiares); apoiados por serviços formais, (apoio social e/ou saúde) ou não; em coabitação com o familiar ou não; a residir na região de Lisboa e Vale do Tejo e em situação de reforma, desemprego ou inseridos no mercado de trabalho. Como doenças crónicas foram consideradas a doença Oncológica, Alzheimer, Parkinson, AVC. É de referir que um dos critérios utilizados foi o familiar se encontrar numa situação de total dependência face a uma terceira pessoa para a execução de todas as actividades da vida diária (pessoais e instrumentais).

6 Foram entrevistados no total 15 homens e 37 mulheres. Dos 27 cuidadores de dupla carreira, 11 encontravam-se em situação de baixa, desemprego, exerciam funções sazonais ou interromperam temporariam ente o trabalho para prestar cuidados. As profissões dos entrevistados variavam, desde as profissões intelectuais e científicas, seguidas das administrativas ou ligadas aos serviços. De forma quase equitativa, surgiam os operários/ artífices e os trabalhadores não qualificados. As situações de baixa por incapacidade perante o trabalho, atingiam na sua totalidade, o pessoal não qualificado (ligados aos serviços de limpeza) e a situações de desemprego ou de baixa, abrangiam em maior número o pessoal administrativo, serviços e operários/ artificies.

7 A Lei $n^{\circ}$ 35/2004, de 29 de Julho que aprovou o novo código do trabalho prevê faltas para assistência a membros do agregado familiar (art. 203) - "o trabalhador tem direito a faltar ao trabalho até 15 dias por ano, para prestar assistência inadiável e imprescindível, em caso de doença ou acidente, ao cônjuge, parente ou afim na linha recta ascendente, ou no 20 grau da linha colateral, filho, adoptado ou enteado com mais de 10 anos". Estas faltas são justificadas, mas não remuneradas. Como refere o art. 204 "as faltas previstas no número anterior, não determinam a perda de quaisquer direitos e são consideradas, salvo quanto à retribuição, como prestação efectiva de serviço". O novo código do trabalho veio uniformizar a lei e estender os mesmos direitos ao regime de trabalho especial na Administração Pública, através do art. $110^{\circ}$ que regula as faltas para assistência a membros do agregado familiar. Contudo, a Direcção- Geral da Administração Pública, com a orientação técnica no 1/DGAP/2006, de 24 de Fevereiro, veio considerar o art $0110^{\circ}$ om isso, relativam ente aos efeitos remuneratórios, pelo que no regime de trabalho especial na Administração Pública, a regulamentação das faltas rege-se pelo Decreto-lei no 100/99, 31 de Março. Segundo este, as faltas para acompanhamento de familiar a exames, tratamentos e consultas médicas, podem ser justificadas, desde que comprovadas por entidade hospitalar ou médica, e indicada a necessidade do acompanhamento. Este disposto é extensivo ao cônjuge ou equiparado, ascendentes, descendentes, adoptandos, adoptados e enteados, menores ou deficientes, em regime ambulatório. As horas dispendidas, são convertidas através da soma em dias completos de faltas e produzem os efeitos das faltas para assistência a familiares", não havendo

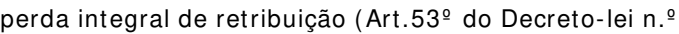
100/99, de 31 de Março).

8 O inquérito dirigido aos empresários e directores de pessoal de 1000 empresas, a nível nacional, em todos os sectores de actividade, com excepção da agricultura, silvicultura, caça e pescas.

9 Das $4,8 \%$ das empresas que referiu a existência de medidas foram especificadas, a aplicação de horários flexíveis e a existência de um apoio técnico de serviço social. (CITE, 1995: 19).

${ }^{10}$ Muito embora os representantes das empresas considerem que as faltas por assistência a idosos não provoquem efeitos negativos, o que é certo, relativamente à questão quem faltava mais ao trabalho, $60 \%$ dos inquiridos respondeu serem as mulheres, $15 \%$ os homens e $25 \%$ por ambos (CITE, 1995: 19).

${ }^{11}$ Daí que seja fundamental a criação de uma estrutura de defesa dos direitos sociais dos mais velhos, à sem elhança do que existe para a infância, estrutura vocacionada para a prevenção e combate à violência familiar e institucional.

${ }^{12}$ Estas estruturas assentam num novo modelo de gestão em que o espaço e toda a organização funcional dos serviços são estruturados em função das características e necessidades das pessoas com demência. Contam-se algumas experiências positivas como o grupo Saumon (Áustria), Cantou (França), Domus (Inglaterra), Group Living (Suécia).

${ }^{13}$ A Lei $n$ ํ 67-A/2007, de 31 de Dezembro - I série $n$ ํ 251 prevê em relação às despesas com ascendentes dois tipos de deduções à colecta: despesas de saúde - "aquisição de outros bens e serviços directamente relacionados com despesas de saúde do sujeito passivo, do seu agregado familiar, dos seus ascendentes e colaterais até ao $3^{\circ}$ grau, desde que devidamente justificados através de receita médica, com o limite de $€ 62$ ou de $2,5 \%$ das importâncias referidas nas alíneas a), b) e c), se superior (art. $82^{\circ}$ ); despesas com encargos com lares "são dedutíveis à colecta $25 \%$ dos encargos com lares e instituições de apoio à terceira idade relativos aos sujeitos passivos, bem como dos encargos com lares e residências autónomas para pessoas com deficiência, seus dependentes, ascendentes e colaterais até ao 3 o grau que não possuem rendimentos superiores à retribuição mínima mensal, com o limite 
de $85 \%$ do valor da retribuição mínima mensal” (artigo $\left.84^{\circ}\right)$.

\section{Referências bibliográficas}

ANDERSON, R. (1998), "Trabalhar e cuidar de idosos - uma perspectiva europeia", in M. D. Guerreiro (coord), Trabalho, Famílias e Gerações - conciliação e solidariedades, Lisboa, CIES/ /ISCTE, pp. 185-192.

AAVV (1998), Déclaration de Vienne de la Conférence Internationale Spécialisée - Vieillir en Europe: la solidarité entre les générations, base de la cohésion sociale, Viena, Federal Ministry for the Environment, Youth and Family Affairs.

BARBERGER-GATEAU, P. e K. Pérés (2001), "Evolution de I' incapacité entre 75 et 84 ans", Gérontologie et Société, 98, pp. 49-64.

CARRILHO, M. J. e L. Patrício (2005), "A situação demográfica recente em Portugal", Revista de Estudos demográficos, 38, pp. 111-140.

COMISSÃO PARA A IGUALDADE NO TRABALHO E NO EMPREGO (1995), Inquérito às medidas de apoio aos trabalhadores com idosos a cargo, Lisboa, CITE, pp. 1-29.

CONSELHO DA EUROPA (1995), A Situação de dependência face à protecção assegurada pela segurança social (VI Conferência dos Ministros Europeus responsáveis pela Segurança Social), Lisboa, 29-31 de Maio de 1995.

DELPERRE, N. (1998), "Les malades d'Alzheimer: politiques européennes de prise en charge", Revue Belge de Sécurité Sociale, 2, pp. 283-300 .

ENNUYER, B. (2002), Les malentendus de la dépendance - De I'incapacité au lien social, Paris, Dunod.

EUROSTAT (2002), The social situation in the European Union, European Comission.

EUROSTAT (2003), The social situation in the European Union, European Comission.

EUROSTAT (2004), The social situation in the European Union, European Comission.

FERNANDES, A. A. (1997), Velhice e Sociedade, Oeiras, Celta.

FERNANDES, A. A. (2007), "Determinantes da mortalidade e da longevidade: Portugal numa perspectiva europeia (EU-15, 1991-2001), Análise Social, 183 (XLII, 2ㅇ Trimestre), pp. 419-443.

FRIES, J. F. (1998), "Aging, natural death, and the compression of morbility", The New England Journal of Medicine, 303, pp. 130-135.

GIL, A. P. M. (1998), Solidariedades intergeracionais e Instituições de Velhice, Dissertação de Mestrado em Sociologia - Família e População, Évora, Universidade de Évora.

GIL, A. P. M. (2007), Heróis do quotidiano: dinâmicas familiares na dependência, Dissertação de Doutoramento em Sociologia, Lisboa, Faculdade de Ciências Sociais e Humanas da Universidade Nova de Lisboa.

GONZÁLEZ, M. D. P. (2001), Dependencia y necesidades asistenciales de los mayores en España. Previsión al año 2010, Fundación Pfizer.

INSTITUTO NACIONAL DE ESTATÍSTICA (INE) (1999), Inquérito à Ocupação do tempo, Lisboa, INE.

INSTITUTO NACIONAL DE ESTATÍSTICA (INE) (2000), Esperança de Vida Sem Incapacidade - 1995 1996, Lisboa, INE.

JACOBZONE, E. e E. Cambois e J. M. Robine (2000), "La Santé des personnes âgées dans les pays de L'OCDE s'améliore-t-elle assez vite pour compenser le vieillissement de la population?", Revue Économique de L'OCDE, 30, pp. 159$-203$.

JONG-GIERVELD, J. e H. V. Solinge (1995), "Le vieillissement et ses conséquences sur le système sociomédical“, Etudes démographiques, 29, Collection Démographie, Conseil de L' Europe.

LAVOIE, J.-P. (2000), Familles et soutien aux parents âgés dépendants, Paris, L'Harmattan.

KRAMER, M. (1980), "The rising pandemic of mental disorders and associated chronic diseases and disabilities", Acta Psychiatrica Sandinavica, 62 (suppl.283), pp. 382-97.

MAGALHÃES, M. G. (2002), "Projecções de população residente, Portugal, 2000/2050 - que tendências de base para a construção de hipóteses?", Revista de Estudos Demográficos, 32, INE, pp. 51-57.

MARIN, D. C. e G. L. Casasnovas (2001), "Vejez, dependencia y cuidados de larga duración - situación actual y perspectivas de futuro", Colección Estudios Sociales, 6, Madrid, Fundación La Caixa.

MERRILL, D. (1997), Caring for elderly parents - juggling work, family and caregiving in middle and working class families, London, Auburn House.

MINISTÉRIO DO TRABALHO E DA SEGURANÇA SOCIAL (2005), Plano Nacional de Emprego, Lisboa, MTSS.

MISSOC (2004), "Social Protection in the Member States of the European Union, of the European Economic Area and in Switzerland", Employment \& Social Affairs, European Commission.

MONTGOMERY, R. (1999), "The family role in the context of long-term care", Journal of Aging and Health, 11 (3), pp. 383-416.

MORMICHE, P. (1997), "Vie et santé progressent de concert", in J. Dupâquier (dir.), L'espérance de vie sans incapacités, Paris, PUF, pp. 93-133.

OCDE (2005), "Les soins de longue durée pour les personnes âgées", Editions OCDE.

PERISTA, H., I. Baptista, F. Freitas, P. Perista e D. Canço (1997), (Re) inventar solidariedades - o local como eixo dinamizador do apoio social às pessoas idosas. Que inovação possível?, Lisboa, CESIS.

PESTANA, N. N. (2003), "Trabalhadores mais velhos, Políticas públicas e práticas empresariais", 
Cadernos de Emprego e Relações de Emprego, 1, MSST/ DGERT.

PRESIDÊNCIA DO CONSELHO DE MINISTROS E MINISTÉRIO DO TRABALHO E DA SOLIDARIEDADE - Comissão para a Igualdade no Trabalho e no Emprego, (2001), Guia de boas práticas para a conciliação da vida familiar e Professional, Lisboa, DEPP.

QUARESMA, M. L. (1996), Cuidados familiares aos idosos, Lisboa, DGAS.

SUNDSTROM, G. (1994), "Les solidarités familiales: tour d'horizon des tendances", Études de politique sociale, 14 [Protéger les personnes âgées dépendantes], Paris, OCDE, pp. 15 -58.
THOMAS, H. (1996), Vieillesse Dépendante et Désinsertion Politique, Paris, L' Harmattan.

TORRES, A. (coord) (2004), Homens e mulheres entre família e trabalho, Estudos, 1, Lisboa, Presidência do Conselho de Ministros, MSST, CITE.

WALL, K., J. São José e S. V. Correia (2002), Trabalhar e cuidar de um idoso dependente: problemas e soluções, Working Paper, Lisboa, Instituto de Ciências Sociais da Universidade de Lisboa", www.ics.ul.pt, pp.1-41.

WHO (2002), Active Ageing. A policy framework. A contribution of the WHO to the Second United Nations World Assembly on Aging, Madrid, WHO.

WATSON, E. e J. Mears (1999), Women, Work and Care of Elderly, Sydney, Ashgate. 